\title{
Confirmatory and supportive laboratory investigations in SARS-CoV-2 infection; a systematic review
}

\author{
Eranga Harshani Silva ${ }^{1 *}$, Sarath Lekamwasam ${ }^{2}$ \\ ${ }^{1}$ Department of Medical Laboratory Science, Faculty of Allied Health Sciences, University of Ruhuna, Galle, Sri Lanka \\ ${ }^{2}$ Department of Medicine, Faculty of Medicine, University of Ruhuna, Galle, Sri Lanka
}

\section{Correspondence to: Eranga Harshani Silva, Email: eranga.silva@yahoo. com, ehsilva@ahs.ruh.ac.lk, slekamwasam@gmail.com}

Received: 14 June 2020 Accepted: 29 June 2020 ePublished: 6 July 2020

Keywords: COVID-19, SARS-CoV-2, Coronavirus, Confirmatory tests, Supportive tests

\section{Citation: Silva $\mathrm{EH}$, Lekamwasam S. Confirmatory and supportive laboratory investigations in SARS- CoV-2 infection; a systematic review. J Prev Epidemiol. 2020;5(1):e03. doi: $10.34172 /$ jpe.2020.03.}

\begin{abstract}
The pandemic of coronavirus disease 2019 (COVID-19) caused by severe acute respiratory syndrome coronavirus 2 (SARS-CoV-2) has spread over 210 countries. In order to mitigate the epidemic and to flatten the curve, apart from multiple containment measures, an accurate identification of those infected is imperative. The objective of this review was to review, systematically, the performance of diagnostic and screening technologies and the yield of different clinical samples for the detection of SARS-CoV-2. Here we have critically evaluated the results obtained from different clinical samples and laboratory investigations and the performance of rRT-PCR (real-time reverse transcriptase polymerase chain reaction) technique in the diagnosis of SARS-CoV-2.
\end{abstract}

\section{Introduction}

An outbreak of severe acute respiratory syndrome (SARS) due to coronavirus was reported from Wuhan, a town in Hubei province of China on December 12, 2019 (1). The epidemic was traced to Huanan seafood market in Wuhan and immediate genomic studies conducted using clinical samples from infected subjects revealed that the causative organism is of bat origin (1). The World Health Organization (WHO) declared the outbreak as a public health emergency first, and later as a pandemic. The common presenting symptoms of coronavirus disease 2019 (COVID-19) include fever, dry cough, shortness of breath, diarrhoea and vomiting (1) although uncommon presentations such as myocarditis and sudden death were also seen. At the time of writing this review (April 11, 2020) COVID-19 caused by severe acute respiratory syndrome coronavirus 2 (SARSCoV-2) has spread over 210 countries, infecting nearly 1.7 million people and causing over 100000 deaths, globally (2). In Sri Lanka, since the detection of first case on $11^{\text {th }}$ February 2020, 197 positive cases have been reported with 7 deaths up to date. In order to prevent rapid spread of infection island-wide and to flatten the curve, the relevant authorities have launched an extensive search to trace contacts and isolate them.
The accurate diagnosis of COVID-19 is crucial since the symptomatology of the disease is not pathognomonic and can be seen in upper respiratory infections caused by many other pathogens. Furthermore, early diagnosis facilitates the isolation of COVID-19 patients from other patients to prevent cross infections and also health care workers to take adequate precautions in handling patients. Protecting frontline medical staff is a priority in a pandemic as the loss of workforce can weaken the health care services which are already overwhelmed by rapid patient turn over. Detecting COVID-19 antigen in respiratory tract secretions or aspirates is the most appropriate method to detect infection early. Detection of specific antibody (IgM) against COVID-19 requires minimum of 7 days from the time of infection limiting its use in the acute management of patients. Certain degree of uncertainty, however, exists among clinicians regarding the performance of antigen detection methods and the most appropriate samples used in the diagnosis of COVID-19.

The objectives of this review were to critically assess the evidence related to the performance of different diagnostic or screening tests and clinical samples in the detection of SARS-CoV-2 
Core tip

This review will be helpful in making decisions on laboratory diagnosis of SARS-CoV-2 infection including sample collection. Further, the findings of this review can be used for future studies and medical education related to SARS-CoV-2 infection and any possible viral outbreak expected in future.

\section{Methods}

The systematic search was conducted in PubMed using the search terms, ["Coronavirus" or "Covid-19" or "SARS-Cov2"] and ["Diagnostic methods" or "Screening methods"] and a total of 407 articles were found. Separate searches were done in the OVID and EMBASE using similar methods. "Similar articles" facility in PubMed and the citations of previous reviews were used to check for missing articles.

The steps described in the PRISMA guidelines (3) were followed during this review. All the articles were screened by the two authors independently in blinded manner using a set of selection criteria. Uncertainties were resolved after discussions and 30 original articles were selected for the review (Figure 1, Table 1).

Inclusion criteria: Original research on laboratory investigations, English language publications, human studies

Exclusion criteria: Reviews, clinical trials.

PCR for COVID-19 antigen

Real-time reverse transcriptase polymerase reaction (rRT-
PCR) is the diagnostic or the screening test commonly used to detect the SARS-CoV-2 in clinical specimens, currently (4). Different studies have reported the use of clinical samples from different body sites from infected individuals. These included nasopharyngeal swabs (58) nasopharyngeal aspirates (5), oropharyngeal swabs (4), urine $(4,6)$ stool (6), serum (4), plasma, sputum (6, 8 -10) throat swabs $(8,10,11)$, broncho-alveolar lavage fluid (BALF) (12) and anal swabs (13).

Samples taken from the respiratory tract have given positive results in the initial stages of the infection in most of the studies $(4,5)$. Serum and plasma were not positive for up to day $7^{\text {th }}(4)$ and even day $20^{\text {th }}(5)$ of the illness in some studies. Serum from one of the two cases in Korea reported to be positive only on the day $8^{\text {th }}$, but the cycle threshold (ct) value was near the cut-off value (14). According to viral load kinetics, following the initial increase, viral load tends to decrease from day $7^{\text {th }}$ in upper and lower respiratory tract (14). Further, in urine and stool samples, viral load has not been sufficient to be considered positive, despite the presence of mild diarrhoea in the patients (14).

Lo et al, have discussed the importance of using nasopharyngeal specimens for SARS-CoV-2 detection. In their study $90 \%$ of the cases were diagnosed using nasopharyngeal specimens. However, in one patient, diagnosis was confirmed using a sputum sample after a negative and an inconclusive result from NPS samples. In contrast to other analyses, authors reported $90 \%$ viral

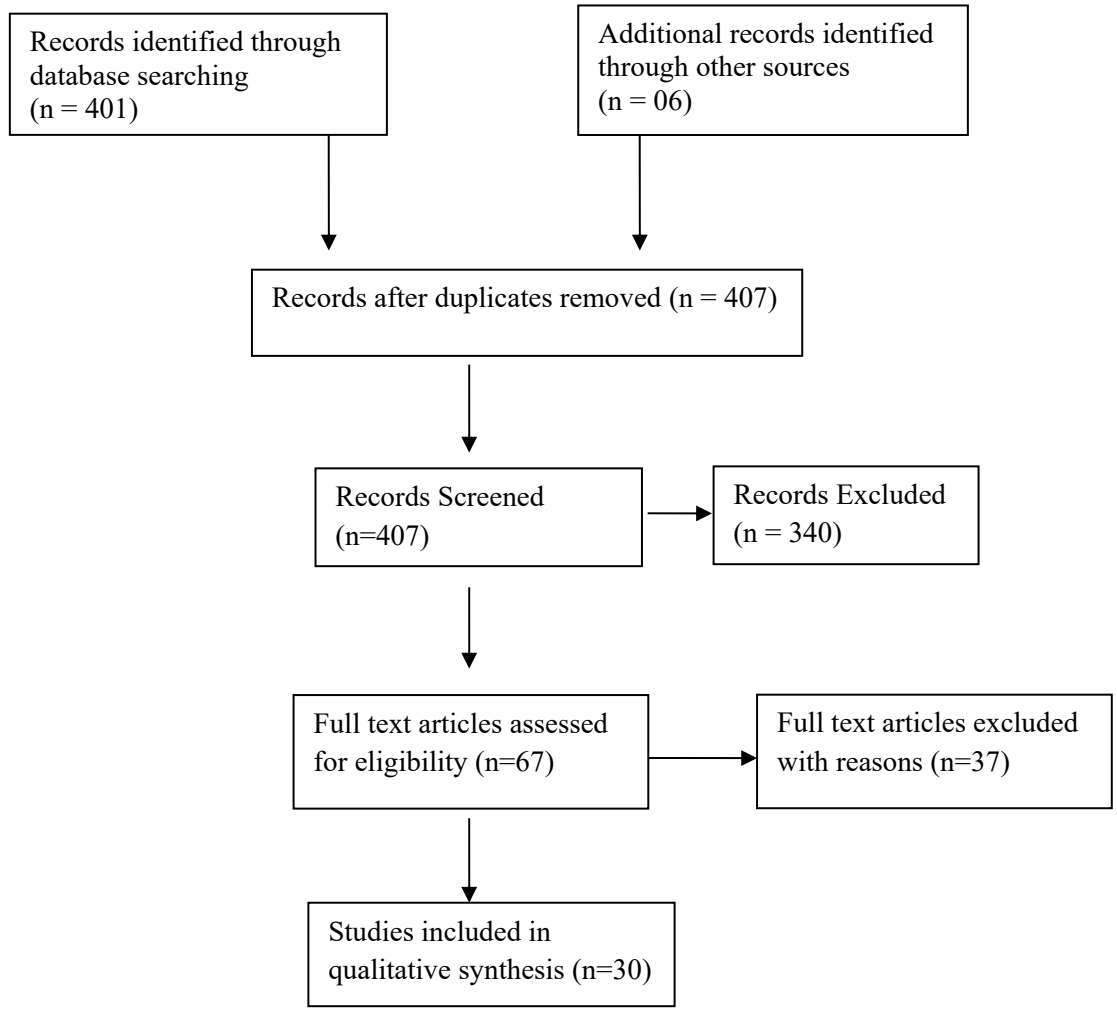

Figure 1. PRISMA flow chart showing the selection of articles for review. 
Table 1. Summary of the clinical studies included in the review

\begin{tabular}{|c|c|c|c|c|c|}
\hline Reference & $\begin{array}{l}\text { Level of } \\
\text { evidence }\end{array}$ & $\begin{array}{l}\text { No. of } \\
\text { patients }\end{array}$ & Symptoms presented & Samples tested & Test/s done \\
\hline Wu et al ${ }^{1}$ & Case report & 1 & $\begin{array}{l}\text { Severe respiratory syndrome with } \\
\text { fever, dizziness and a cough }\end{array}$ & BALF & Metagenomic RNA sequencing \\
\hline Holshue et al ${ }^{4}$ & Case report & 1 & Fever, cough & $\begin{array}{l}\text { NPS, OPS, Stool, } \\
\text { Serum, Urine }\end{array}$ & $\begin{array}{l}\text { rRT-PCR, CBC, Glu, BUN, Cr, TP, AI, TB, ALT, AST, } \\
\text { ALP, Fib, LDH, PT, INR, CK, VL }\end{array}$ \\
\hline Haveri et al ${ }^{5}$ & Case study & 1 & $\begin{array}{l}\text { Runny nose, nausea, fever, } \\
\text { weakness, cough }\end{array}$ & NPS, NPA, serum & rRT-PCR, Antibody response \\
\hline Lo et $\mathrm{al}^{6}$ & Cross-sectional & 10 & $\begin{array}{l}\text { Fever, diarrhoea, cough, dyspnea, } \\
\text { sore throat, nausea, myalgia, } \\
\text { rhinorrhea, nasal congestion, } \\
\text { dizziness, abdominal pain }\end{array}$ & $\begin{array}{l}\text { NPS, sputum, } \\
\text { urine, faeces }\end{array}$ & qRT-PCR \\
\hline Han et $\mathrm{al}^{7}$ & Case study & 1 & $\begin{array}{l}\text { Fever, cough, white phlegm, stuffy } \\
\text { and runny noses, vertigo, fatigue, } \\
\text { chest tightness, nausea, bosom } \\
\text { frowsty }\end{array}$ & NPS & $\begin{array}{l}\text { rRT-PCR, CBC, CRP, Pr, AST, Tr, LDH, CK, Fib, Dd, } \\
\text { Glu. }\end{array}$ \\
\hline Chan et al ${ }^{9}$ & Family cluster & 6 & Fever, respiratory symptoms & $\begin{array}{l}\text { NPS, TS, Stool, } \\
\text { urine }\end{array}$ & $\begin{array}{l}\text { rRT-PCR, whole genome sequencing, CBC, PT, INR, } \\
\text { APTT, Dd, Fib, CRP, Al, TB, ALT, ALP, AST, Urea, Cr, } \\
\text { Electrolytes, CK, LDH, Amy }\end{array}$ \\
\hline Zhou et al ${ }^{11}$ & $\begin{array}{l}\text { Retrospective } \\
\text { cohort }\end{array}$ & 191 & Fever, cough, dyspnoea, fatigue & TS & $\begin{array}{l}\text { Next generation sequencing or rRT-PCR, CBC, PT, } \\
\mathrm{Cr}, \mathrm{Al}, \mathrm{ALT}, \mathrm{LDH}, \mathrm{CK}, \mathrm{Hs}-\mathrm{CTI}, \mathrm{Dd}, \mathrm{SF}, \mathrm{IL}-6, \mathrm{Pr}\end{array}$ \\
\hline Liu et al ${ }^{12}$ & Cross-sectional & 12 & Fever, cough, myalgia, diarrhoea & TS, BALF & $\begin{array}{l}\text { rRT-PCR, CBC, ALB, CRP, LDH, CD8, CK, Myo, CTI, } \\
\text { BNP, CK-MB }\end{array}$ \\
\hline Chen et al ${ }^{13}$ & Retrospective & 57 & Fever & PS, blood, AS & rRT-PCR \\
\hline Kim et al ${ }^{14}$ & Cross-sectional & 2 & Fever, chills, myalgia, sore throat & $\begin{array}{l}\text { NPS, OPS, urine, } \\
\text { stool, serum, } \\
\text { plasma }\end{array}$ & rRT-PCR \\
\hline Zou et al ${ }^{16}$ & Cross-sectional & 18 & NR & NS, TS & rRT-PCR \\
\hline Li et al ${ }^{17}$ & Case report & 2 & $\begin{array}{l}\text { Fever, dry throat, difficulty } \\
\text { breathing, nausea, vomiting, } \\
\text { diarrhoea }\end{array}$ & TS & rRT-PCR, CBC \\
\hline Zhang et al ${ }^{19}$ & Retrospective & 95 & NR & NS, PS & CBC, CRP, Dd, ALT, AST, Cr, $\alpha-\mathrm{HBD}, \mathrm{LDH}, \mathrm{CK}, \mathrm{TP}$ \\
\hline Chen et $\mathrm{a}^{20}$ & Retrospective & 99 & $\begin{array}{l}\text { Fever, cough, shortness of breath, } \\
\text { muscle ache, confusion, headache, } \\
\text { sore throat, rhinorrhoea, chest pain, } \\
\text { diarrhoea, and nausea and vomiting }\end{array}$ & $\begin{array}{l}\text { TS, sputum, } \\
\text { endotracheal } \\
\text { aspirates }\end{array}$ & $\begin{array}{l}\text { rRT-PCR, CBC, APTT, PT, Dd, Al, ALT, AST, TB, BUN, } \\
\text { Cr, CK, LDH, Myo, Glu, Pr, IL-6, ESR, SF, CRP }\end{array}$ \\
\hline Chen et al ${ }^{24}$ & Case study & 2 & Fever, cough & BALF & $\begin{array}{l}\text { Metagenomic next-generation sequencing, CBC, Al, } \\
\text { AST, CK, CK-MB, LDH, Urea, Cr }\end{array}$ \\
\hline Lan et $\mathrm{al}^{28}$ & Cross-sectional & 4 & NR & TS & rRT-PCR \\
\hline Zhou et al ${ }^{29}$ & Cross-sectional & 7 & Severe pneumonia & $\begin{array}{l}\text { Oral swabs, AS, } \\
\text { BALF, serum }\end{array}$ & Metagenomic RNA sequencing \\
\hline
\end{tabular}

BALF; broncho alveolar lavage fluid, NPS; nasopharyngeal swab, OPS; oropharyngeal swab, NPS; nasopharyngeal aspirate, TS; throat swab, PS; pharyngeal swab, AS; anal swab, NS; nasal swab, rRT-PCR; real time reverse transcriptase polymerase chain reaction, CBC; complete blood count, Glu; glucose, BUN; blood urea nitrogen, $\mathrm{Cr}$; serum creatinine, TP; total protein, $\mathrm{Al}$; albumin, TB; total bilirubin, ALT; alanine transaminase, AST; aspartate transaminase, ALP; alkaline phosphatase, Fib; fibrinogen, LDH; lactate dehydrogenase, PT; prothrombin time, INR; international normalized ratio, CK; creatine kinase, VL; venous lactate, qRT- PCR- quantitative reverse transcriptase polymerase chain reaction, CRP- C-reactive protein, CTI; cardiac troponin I, Pr; prolactin, Tr; troponin, Dd; D-dimer level, Amy; amylase, Hs-CTI; high sensitivity cardiac troponin I, SF; serum ferritin, IL-6, interleukin 6, Myo; myoglobin, BNP; brain natriuretic peptide, $\alpha$-HBD- alpha hydroxybutarate dehydrogenase, ESR; erythrocyte sedimentation rate.

positivity in faecal samples of these patients. Moreover, in one patient, the virus has been detected in faeces up to 14 days from the onset of symptoms (6). This observation was in par with the first case reported from the United States (4) but in contrast to the observations made by Kim et al (14). Apart from the respiratory tract, SARSCoV-2 has an increased affinity for gut mucosa due to the expression of cell receptor angiotensin converting enzyme II in absorptive enterocytes in the ileum and colon (15). Some have suggested testing NPS and faecal samples simultaneously to improve the detection rate so that infected subjects are not released to the society (6). In addition, it is also important to know whether the anal tract is a possible transmission route for the virus as viral shedding was common in faeces although viability of the virus is unknown (6). Further it is evident that in some cases virus RNA conversion in the stool sample is delayed (6). Therefore, patients with negative NPS and positive stool samples may be undergoing the convalescent phase but they may remain infective (6).

Liu et al, comparing the results of throat swabs and BALF in three patients, found BALF to give positive results while throat swabs were negative, indicating that BALF may be more reliable than throat swab for the detection of SARSCoV-2 (12). However, they also report a patient in whom BALF was negative while throat swab was positive (12).

After analysing viral load in 17 throat and nasal swabs of symptomatic patients, Zou et al found nasal swabs to 
have higher viral load compared to throat swabs. These samples have been obtained soon after the onset of symptoms and the authors have suggested that viral RNA shedding of SARS-CoV-2 resembles that of influenza but different from SARS-CoV-2 (16). The false negative results observed by Dasheng et al, may be due to the low viral load present in the throat swabs (17). These findings highlight the importance of using the most suitable specimens for viral detection and also the need of analysing samples from multiple sites.

Chen et al have studied viral replication in extrapulmonary sites of the body and whether patients with severe symptoms show difference in virus replication and distribution compared to patients who exhibit milder symptoms (13). Blood, pharyngeal swabs and anal swabs were collected from confirmed COVID-19 cases and patients were divided according to the symptoms as mild and severe (13). In this analysis, compared to blood negative group, blood positive group showed severe disease. The viral RNA positivity in anal swabs also showed a significant positive correlation with disease severity. Once again these findings indicate that the digestive tract is an extrapulmonary site where viral replication takes place. Authors have proposed that increased viral load in the lungs can be released to blood via damaged alveoli, resulting viral spreading throughout the body and later re-infecting the digestive tract through ACE-2 (13). The detection of viral RNA in extrapulmonary sites is a serious concern as these patients would require extra precautions in nursing (13). However, some researchers have claimed that the presence of viral RNA in extrapulmonary sites does not necessarily indicate the presence of the infectious virus in those sites (4).

\section{Differential diagnoses}

Studies from Italy (18), United States (4), and China (9) have highlighted the importance of considering alternative diagnoses in patients suspected of SARS-CoV-2. Bordi et al, have investigated 126 suspected cases in Italy, using a rapid molecular test (QIAstat-Dx respiratory panel (QIAGEN, Milan, Italy)) and found that 53.2\% of patients were positive for respiratory pathogens(viral or bacterial) other than SARS-CoV-2. Influenza virus was the commonest among suspected individuals and only three out of 126 were tested positive for SARS-CoV-2 by rRT-PCR technique (18). Screening suspected cases with broad spectrum diagnostic panel is of immense help in clinical management and making containment decisions on patients especially during an outbreak (18).

\section{Other laboratory investigations}

Other laboratory abnormalities seen in patients with SARS-CoV-2 include leukopenia (4), leucocytosis (11), lymphopenia $(6,7,11,12)$ mild thrombocytopenia $(4,9,19)$, hypoalbunaemia (12), hypoprotenaemia (19),decreased CD 8 count (12), elevated creatinine kinase (CK) $(4,11,19)$, alkaline phosphatase (ALP) (4), alanine aminotransferase (ALT) $(4,19)$, aspartate aminotransferase (AST) $(4,19)$, lactate dehydrogenase $(\mathrm{LDH})(4,6,9,12,19) \mathrm{d}$-dimer (DD) $(11,19)$, serum ferritin(SF) (11), high sensitivity cardiac troponin I (11) (hs-CTI), Interleukin-6(IL-6) (11), prothrombin time(PT) (11), procalcitonin (Pr) (11), creatinine $(\mathrm{Cr})(11,19)$, C-reactive protein (CRP) $(7,9,12,19,20)$, fibrinogen (9), activated thromboplastin time (APTT) (9), a-hydroxybutyrate dehydrogenase ( $\alpha$-HBD) (19).

Zhou et al revealed that leucocytosis, lymphocytopenia, elevated ALT, LDH, hs-CTI, CK, DD, SF, IL-6,PT, Pr and $\mathrm{Cr}$ were associated with increased mortality. In addition, DD levels higher than $1 \mu \mathrm{g} / \mathrm{mL}$ on admission were also associated with increased likelihood of death, indicating that disruption of coagulation process is a surrogate of severe disease (11). In addition, baseline lymphocyte count of survivors has been significantly higher compared to the non-survivors. Further, the lowest lymphocyte count was seen on the day 7 among survivors and improved afterwards whereas in non-survivors lymphopenia persisted until death. Moreover, in the non-survivors, a rapid increase of hs-CTI was observed from day 16 (11).

Li et al reported a patient who had normal leukocyte counts and increased lymphocyte count in contrast to the majority of the patients (17).

Correlations between viral load and serum albumin, and blood lymphocytic and neutrophil counts have been reported by Liu et al recently. Further they found lung injury to be associated with alteration of serum albumin, lymphocyte count and percentage, neutrophil percentage, LDH, and CRP (12). In addition, they found hypoalbuminaemia, lymphopenia, and elevated levels of $\mathrm{CRP}$ and LDH to be strong predictors of severe acute lung injury on admission (12).

When compared with patients with mild or moderate disease, patients with severe infection had higher AST, $\mathrm{LDH}$ and leucocyte and neutrophil counts. Further, serum CRP was associated with severe infection (6).

According to Zhang et al, compared to leukopenia, leucocytosis is more related to the severity of the disease and this is believed to be due to the excessive inflammation and tissue injury seen in severely ill patients. Further, neutrophilia was associated with pneumonia and composite clinical endpoints of SARS-CoV-2 patients. Even in the presence of leucocytosis, lymphopenia was a regular feature in these patients and this was believed to be due to the translocation of lymphocytes from peripheral blood to the lungs (19). Though viral RNA was detected in urine, significant difference was not found in serum creatinine between severe and non-severe patients. Elevated LDH, $\alpha-\mathrm{HBD}$ and CK were found in $77.9 \%, 92.6 \%$ and $29.5 \%$ of patients possibly due to acute myocardial injury (19). Zhang et al, however, excluded patients with chronic underlying diseases in this analysis which could have an impact on the results of laboratory examinations (19). 


\section{Role of the genetic tests}

In an outbreak of this nature, it is important to know the duration and the level of virus replication in order to assess the risk of transmission and to decide on the isolation procedures (11). Genomic sequencing or nucleic acid tests are considered the gold standard for detection of the viral infection (17). As viral RNA detection is more sensitive than virus isolation, almost all the studies have used qualitative or quantitative viral RNA detection tests as the marker of choice to diagnose SARS-CoV-2 infection (11). The commonly used tests for viral detection include rRT-PCR $(5,17)$ and qRT-PCR $(12)$ tests. The target genes of the real time RT-PCR tests include the Envelope (E) (5, 21), the RNA dependent RNA Polymerase (RdRP) (5, 9, 21), nucleocapsid (N) $(5,12,22)$, Spike (S) (9), and ORF1b $(12,22)$ genes.

Corman et al have recommended using E gene assay for routine screening and RdRP as the confirmatory assay, as they have shown higher sensitivity. They have obtained less sensitivity for $\mathrm{N}$ gene (8).

Konrad et al have also concluded that E gene assay was more sensitive compared to the two RdRP assay combined with a system of one step RT-PCR. However, E gene assay has given more background signals disturbing the assay results (21).

$\mathrm{Chu}$ et al reported that the sensitivity of $\mathrm{N}$ gene assay was 10 times higher than the ORF1b gene assay (22). They have suggested that the increased expression of subgenomic mRNA in the clinical samples gives rise to higher $\mathrm{N}$ gene copies. Considering these results, it was recommended using $\mathrm{N}$ gene assay as the screening assay and the ORF1b assay for the confirmation (22).

In the study by Chan et al, all respiratory samples gave positive results with both RdRP and $S$ genes with conventional RT-PCR and only for the $S$ gene by rRT-PCR. The phylogenetic analysis of the PCR products revealed that the amplicon sequences of both the genes from all the positive patients were different from previously known coronaviruses of human or animal origin (9). However, complete genome sequences of two strains from two patients were identical to each other and resemble the bat SARS-related coronavirus reported in 2018 (9).

Interestingly, Pfefferle et al have introduced a fully automated system called cobas 6800, an open channel, rapid system, to cope with the increased demand for testing. The advantages of this method include minimal staff training, rapid turnaround time and high sensitivity and specificity of the assay. Cobas 6800 seems to be an alternative for an outbreak where testing becomes a challenge (23).

Chen et al suggest the use of metagenomic next generation sequencing (MNGS), which allows the direct examination of the infectious organism from the clinical sample. The RNA based technique is capable of revealing the entire 'infectome' (RNA viruses, DNA viruses, bacteria, eukaryotes), rapid and accurate diagnosis of a pathogen
(24). In addition, Ai et al suggested a combined approach for SARS-CoV-2 detection using MNGS, rRT-PCR and clustered regularly interspaced short palindromic repeats (CRISPR) based assay (25).

\section{False negative results of rRT-PCR}

rRT-PCR has given false negative results in some instances. Dasheng et al reported false negative rRTPCR test results in throat swab samples taken from two patients with clinical symptoms (17). In one patient two consecutive rRT-PCR tests were negative, and only the third sample has become positive (17). Insufficient specimens and erroneous laboratory procedures are the most likely reasons for these false negative (26). In addition, infection route, stage of the disease progression, specimen collection timing and method and coinfections may also contribute to false positive rRT-PCR results (17). Authors have highlighted the importance of considering clinical manifestations, laboratory investigations and radiological features in the chest $\mathrm{CT}$ in the diagnosis of SARS-CoV-2 infection to overcome the approximately $20 \%$ of false negative rRT-PCR results (17). The National Health Commission of China has revised the criteria for the diagnosis of SARS-CoV-2, with the introduction of 'clinical diagnosis', where diagnosis is based on pneumonia features detected on chest CT, irrespective of rRT-PCR test results (27). Further, rRT-PCR can be applied for making decisions on isolation and timing of discharge (17).

Positive RT-PCR results, however, have been seen in respiratory specimens obtained from recovered patients. This can be due to false negative test results, re-activation or viral residues in the respiratory tract. It is still unclear whether these patients are contagious it is important to adhere to containment measures (28).

\section{Serological investigations}

The serological diagnosis of the SARS-CoV-2 has been analysed in three studies. Zhou et al have used a previously developed nucleocapsid (N) protein from bat SARS$\mathrm{CoV}$ Rp3 as antigen for IgG and IgM enzyme-linked immunosorbent assays (ELISAs). The viral antigen levels have shown a clear trend in IgM and IgG levels, in the days $7,8,9$ and 18 from the onset of the symptoms in a selected patient. However, the IgM titre of the last sample has decreased. Further, after 20 days of disease onset, samples were positive for IgG. In addition, three IgM positive samples were also detected, indicating an acute infection (29).

In the second study, the viral antibodies were undetectable till day 4 from the onset of the disease. From day 9 to day 20, IgM antibodies rose from 80 to 320 and IgG from 80 to 1280 (5).

However, Xu et al reported that in a family cluster of six people, where five of six people were SARS-CoV-2 specific IgM positive but according to the molecular assay only two were positive. They have highlighted the importance 
of performing serology tests for detection of SARS-CoV-2 (30).

\section{Discussion}

There is a paucity of large datasets related to laboratory testing in SARS-CoV-2 infection. This is understandable since it is a new virus detected nearly five months ago. Further, the most of publications are from China and small sample size is a limitation in most of the studies.

Due to small numbers, data is insufficient for a proper head to head comparison of the performance of different analytical methods. The same limitation is observed in deciding the best clinical sample for establishing the diagnosis of COVID-19.

Data related to COVID-19 pandemic is still building up and clinicians and health care providers need to base their decisions on the limited information available. This is clearly evident in therapeutic decision making. Although numerous antiviral medications have been proposed the scientific evidence is not robust to recommend a uniform antiviral treatment. Similar situation prevails in the investigation of patients, this review, however, will help clinicians involved in the care of COVID-19 patients to understand the uses and limitation of the current laboratory investigations of SARS-CoV-2.

According to current evidence, rRT-PCR appears to be the most appropriate method available for the detection of SARS-CoV-2 antigen. The technology is relatively inexpensive. Widely available and can be installed in temporary buildings particularly to facilitate community screening. NP samples have given high positivity particularly in symptomatic patients in the early stage in the illness. The procedure is simple, requires less training and can be done in the community. Bronchoscopic aspiration from the lower respiratory tract, although have given high positivity, can be reserved for selected patients who are negative in initial investigations but have a high clinical suspicion. Detection of viral antigen in stool samples is desirable especially when the presentation is delayed and NG samples have given negative results. Examining samples from multiple sites would increase the detection rate but this may have limitations due to cost considerations. When initial investigations are negative in a patient with suggestive symptomatology, the current evidence is not sufficient to make recommendations whether to repeat the testing of samples obtained from the same site or proceed to testing samples from multiple sites.

\section{Conclusion}

Samples from upper and lower respiratory tract shows increased positivity with SARS-CoV-2 compared to samples from extrapulmonary sites. However, throat swabs were not sensitive enough to detect SARS-CoV-2. Despite drawbacks rRT-PCR appears to be the most logical and practical assay that can be used for community screening. However, moving to fully automated systems or combined approached may enhance SARS-CoV-2 detection.

Authors' contribution

EHS and SL contributed to data gathering. EHS prepared the primary draft and the final edit was conducted by SL. Both authors approved the final version for publication.

Conflicts of interest

All authors have no conflict of interest to declare.

Ethical considerations

Ethical issues (including plagiarism, data fabrication, double publication) have been completely observed by the author.

\section{Funding/Support}

None.

\section{References}

1. Wu F, Zhao S, Yu B, Chen YM, Wang W, Song ZG, et al. A new coronavirus associated with human respiratory disease in China. Nature 2020;579:265-9. doi: 10.1038/s41586-0202008-3.

2. Worldometer, COVID-19 Coronavirus Pandemic. Available from: https://www.worldometers.info/coronavirus/.

3. Preferred Reporting Items for Systematic Reviews and MetaAnalyses (PRISMA). Available from: http://www.prismastatement.org/.

4. Holshue ML, DeBolt C, Lindquist S, Lofy KH, Wiesman J, Bruce H, et al. First Case of 2019 Novel Coronavirus in the United States. N Engl J Med. 2020;382:929-936. doi: 10.1056/ NEJMoa2001191.

5. Anu H, Teemu S, Suvi K, Pamela Ö, Jussi H, Niina I, et al. Serological and molecular findings during SARS-CoV-2 infection: the first case study in Finland, January to February 2020. Euro Surveill 2020;25:2000266. doi: 10.2807/15607917.ES.2020.25.11.2000266

6. Lo IL, Lio CF, Cheong HH, Lei Cl, Cheong TH, Zhong X, et al. Evaluation of SARS-CoV-2 RNA shedding in clinical specimens and clinical characteristics of 10 patients with COVID-19 in Macau. Int J Biol Sci. 2020;16:1698-707. doi: 10.7150/ ijbs. 45357

7. Han W, Quan B, Guo Y, Zhang J, Lu Y, Fenget G, et al. The course of clinical diagnosis and treatment of a case infected with coronavirus disease 2019. J Med Virol. 2020;92:461463. doi: $10.1002 / j m v .25711$

8. Corman VM, Landt O, Kaiser M, Molenkamp R, Meijer A, Chu DKW, et al. Detection of 2019 novel coronavirus (2019-nCoV) by real-time RT-PCR. Euro Surveill 2020;25:2000045. doi: 10.2807/1560-7917.ES.2020.25.3.2000045

9. Chan JFW, Yuan S, Kok KH, To KKW, Chu H, Yang J, et al. A familial cluster of pneumonia associated with the 2019 novel coronavirus indicating person-to-person transmission: a study of a family cluster. Lancet 2020;395:514-23. doi: 10.1016/ S0140-6736(20)30154-9

10. Hoehl S, Rabenau H, Berger A, Kortenbusch M, Cinatl J, Bojkova D, et al. Evidence of SARS-CoV-2 Infection in Returning Travelers from Wuhan, China. N Engl J Med. 2020;382:1278-80. doi: 10.1056/NEJMc2001899

11. Zhou F, Yu T, Du R, Fan G, Liu Y, Liu Z, et al. Clinical course and risk factors for mortality of adult inpatients with COVID-19 in Wuhan, China: a retrospective cohort study. Lancet 2020; 395:1054-62. doi: 10.1016/S0140-6736(20)30566-3

12. Liu Y, Yang Y, Zhang C, Huang F, Wang F, Yuan J, et al. Clinical and biochemical indexes from 2019-nCoV infected patients linked to viral loads and lung injury. Sci China Life Sci. 2020;63:364-374. doi: 10.1007/s11427-020-1643-8 
13. Chen $W$, Lan $Y$, Yuan $X$, Deng $X$, Li Y, Cai X, et al. Detectable 2019-nCoV viral RNA in blood is a strong indicator for the further clinical severity. Emerg Microbes Infect. 2020;9:46973. doi: 10.1080/22221751.2020.1732837

14. Kim JY, Ko JH, Kim Y, Kim YJ, Kim JM, Chung YS, et al. Viral load kinetics of SARS-CoV-2 Infection in first two patients in Korea. J Korean Med Sci. 2020;35:e86 -87. doi: 10.3346/ jkms.2020.35.e86

15. Zhang H, Kang Z, Gong H, Xu D, Wang J, Li Z, et al. The digestive system is a potential route of 2019-nCov infection: a bioinformatics analysis based on single-cell transcriptomes. bioRxiv 2020:2020.01.30.927806. doi: https://doi. org/10.1101/2020.01.30.927806

16. Zou L, Ruan F, Huang M, Liang L, Huang H, Hong Z, et al. SARS-CoV-2 viral load in upper respiratory specimens of infected patients. N Engl J Med 2020.19;382:1177-1179. doi: 10.1056/NEJMc2001737

17. Li D, Wang D, Dong J, Wang N, Huang $\mathrm{H}, \mathrm{Xu} \mathrm{H}$, et al. Falsenegative results of real-time reverse- transcriptase polymerase chain reaction for severe acute respiratory syndrome coronavirus 2: role of deep-learning-based CT diagnosis and insights from two cases. Korean J Radiol 2020;2:505-508. doi: 10.3348/kjr.2020.0146

18. Licia B, Emanuele N, Laura S, Antonino DC, Rosaria CM, Concetta $\mathrm{C}$, et al. Differential diagnosis of illness in patients under investigation for the novel coronavirus (SARS-CoV-2), Italy, February 2020. Euro Surveill 2020;25:2000170. doi: 10.2807/1560-7917.ES.2020.25.8.2000170

19. Zhang G, Zhang J, Wang B, Zhu X, Wang Q, Qiuet S, et al. Analysis of clinical characteristics and laboratory findings of 95 cases of 2019 novel coronavirus pneumonia in Wuhan, China: a retrospective analysis. Respir Res. 2020;21:74. doi: 10.1186/s12931-020-01338-8

20. Chen N, Zhou M, Dong X, Qu J, Gong F, Han Y, et al. Epidemiological and clinical characteristics of 99 cases of 2019 novel coronavirus pneumonia in Wuhan, China: a descriptive study. Lancet. 2020;395:507-13. doi: 10.1016/ S0140-6736(20)30211-7

21. Regina K, Ute E, Alexandra D, Bianca T, Anja B, Katja B, et al. Rapid establishment of laboratory diagnostics for the novel coronavirus SARS-CoV-2 in Bavaria, Germany, February 2020 Euro Surveill 2020;25:2000173. doi: 10.2807/1560-7917. ES.2020.25.9.2000173

22. Chu DKW, Pan Y, Cheng SMS, Hui KPY, Krishnan P, Liu Y, et al. Molecular diagnosis of a novel coronavirus (2019-nCoV) causing an outbreak of pneumonia. Clin Chem. 2020; 66:549555. doi: 10.1093/clinchem/hvaa029

23. Pfefferle S, Reucher S, Nörz D, Lütgehetmann M . Evaluation of a quantitative RT-PCR assay for the detection of the emerging coronavirus SARS-CoV-2 using a high throughput system. Euro Surveill. 2020;25:2000152. doi: 10.2807/1560-7917. ES.2020.25.9.2000152

24. Chen L, Liu W, Zhang Q, Xu K, Ye G, Wu W et al. RNA based mNGS approach identifies a novel human coronavirus from two individual pneumonia cases in 2019 Wuhan outbreak. Emerg Microbes Infect. 2020;9:313-9. doi: 10.1080/22221751.2020.1725399

25. Ai JW, Zhang Y, Zhang HC, Xu T, Zhang WH. Era of molecular diagnosis for pathogen identification of unexplained pneumonia, lessons to be learned. Emerg Microbes Infect. 2020;9(1):597-600. doi: 10.1080/22221751.2020.1738905

26. Xie X, Zhong Z, Zhao W, Zheng C, Wang F, Liu J. Chest CT for typical 2019-nCoV pneumonia: relationship to negative RT-PCR testing. Radiology. 2020;200343. doi: 10.1148/ radiol.2020200343

27. National Health Commission of the People's Republic of China Diagnosis and treatment protocols of pneumonia caused by a novel coronavirus (trial version 5). Beijing: National Health Commission of the People's Republic of China; 2020

28. Lan L, Xu D, Ye G, Xia C, Wang S, Liet Y, et al. Positive RTPCR Test results in patients recovered from COVID-19. JAMA. 2020. doi: 10.1001/jama.2020.2783

29. Zhou P, Yang XL, Wang XG, Hu B, Zhang L, Zhang W, et al A pneumonia outbreak associated with a new coronavirus of probable bat origin. Nature. 2020;579:270-3. doi: 10.1038/ s41586-020-2012-7

30. Xu Y, Xiao M, Liu X, Xu S, Du T, Xu J, et al. Significance of Serology Testing to Assist Timely Diagnosis of SARS-CoV-2 infections: Implication from a Family Cluster. Emerg Microbes Infect. 2020;14:1-12. doi: 10.1080/22221751.2020.1752610 